\section{Depression in Children and Adolescents}

by Prof. Dr. med. Claudia Mehler-Wex, Dr. med. Michael Kölch in volume $9 / 2008$

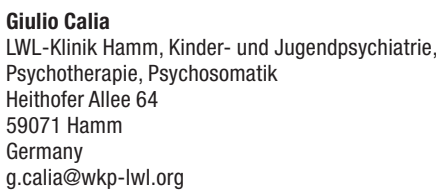

Conflict of interest statement

The author has received postgraduate training on schizophrenia from the company Janssen-Cilag GmbH, who paid his travel costs.

\section{Remember the comorbidities}

The diagnosis of depressive disorders in children and adolescents requires good and profound exploration and expertise. I have seen patients referred with the diagnosis of attention deficit-hyperactivity disorder (ADHD), who have turned out to be suffering from depression. In addition, the symptoms of aggression and agitation in adolescents may serve to mask the manic or hypo-manic phase of bipolar disorder $(1,2)$. Addictive and affective disorders are not rare. Intake of ad-dictive drugs can be a form of self-medication. Depressive symptoms in adolescents may also indicate psychotic development, which may start with purely negative symptoms.

The discussion on the increased risk of suicide during antidepressive treatment has often been biased. There is in fact growing evidence of increases in adolescent suicide because of restraints in prescription. My personal experience concerning the prescription of antidepressives to adolescents with depressive disorders has been positive. In any case, the issue of suicidal tendencies should always be addressed openly and be observed. It must be distinguished from impulses to self-injury or self-injuring behavior, for example, in post-traumatic stress disorder (reduction in stress).

Additional administration of an (atypical) neuroleptic has had favorable results in depressive disor-ders with mood fluctuations, tendency to ruminate and sleep disorders, as well as for suicidal thoughts. We are aware that treatment of depression is unpromising with drugs alone. A current study from the USA (3) demonstrates the superiority of a combination of behavioral therapy and antidepressives. In my experience, the combination of various psychotherapeutic procedures and involvement of the family system can be expedient.

DOI: 10.3238/arztebl.2008.0363a

\author{
REFERENCES \\ 1. Lewinsohn P, Klein D, Seeley J: Bipolar disorders in a community \\ sample of older adolescents: prevalence, phenomenology, co- \\ morbidity, and course. J Am Acad Child Adolesc Psychiatry 1995; \\ 34: 454-63. \\ 2. Carlson GA: Annotation: Child and adolescent mania-diagnostic \\ considerations. J Child Psychology and Psychiatry 1990; 3: \\ 331-41. \\ 3. Brent D, MD, Emsile G, MD, Clarke G, PhD et al.: Switching to \\ another SSRI or to Venflaxine with or without behavioral therapie \\ for adolescents with SSRI-restistant depression - The TORDIA \\ randomized controlled trial. JAMA. 2008; 229: 901-13.
}

\section{Include psychoanalytical procedures}

The authors maintain that there are ,hardly any empirical data are available" for the use of family therapy, client-centered play therapy and deep psychological therapy in the treatment of depressive disorders in children and adolescents, but that level of evidence I for cognitive behavioral therapy and level of evidence II for interpersonal therapy have been demonstrated. This assertion is based on the guidelines for the diagnosis and therapy of psychiatric disorders in babies, children and adolescents. This unambiguously states: "There have been no controlled studies on the use of play therapy or deep psychological therapy in the treatment of depressive children or adolescents."

This assertion is wrong; Controlled studies have been performed by Horn et al. (1) and Muratori et al. (2). Both studies include catamneses and demonstrate significant effects with depressive and dysthymiac patients - corresponding to level of evidence II - and in comparison with either a waiting control group or "treatment as usual". As these are both short term studies (also with recourse to Malan's focal therapy), this also shows that short term psychodynamic interventions are effective. Moreover, other workers, including Trowell et al. (3), have demonstrated the efficacy of psychoanalytical or psychodynamic procedures on the basis of catamneses, as well as naturalistic and comparative therapeutic studies.

These studies have been published and could easily have been found with a little research. This leaves the impression that the scientific research was incomplete, due to a bias towards behavioral therapy. As this has repeatedly happened, particularly in the guidelines, it may be inferred that the intention is to restrict psychoanalytical procedures by marginalizing them. Although it must be admitted that psychodynamic studies are comparatively rare, those that are known should not be withheld or presented as being of little significance.

DOI: 10.3238/arztebl.2008.0363b

\section{REFERENCES}

1. Horn $\mathrm{H}$ et al.: Zur Wirksamkeit psychodynamischer Kurzzeitpsychotherapie bei Kindern und Jugendlichen mit Depressionen. Praxis der Kinderpsychologie und Kinderpsychiatrie 2005; 5: 52-71.

2. Muratori $F$ et al.: Efficacy of brief psychotherapy for children with emotional disorders. Psychother Psychosom 2002; 71: 28-38. 
3. Trowell $\mathrm{J}$ et al.: Childhood depression: a place for psychotherapy: an outcome study comparing individual psychodynamic psychotherapy and family therapy. Eur Child Adolesc Psychiatry 2007; 10: $584 \mathrm{ff}$

Dr. phil. Eberhard Windaus

Länderweg 45

60599 Frankfurt am Main

Germany

Conflict of interest statement

The author declares that no conflict of interest exists according to the guidelines

of the International Committee of Medical Journal Editors.

\section{In Reply:}

We fully agree with the points made by Calia. As the relative intensity of the different symptoms of depressive disorders in children and adolescents varies with age, it is particularly important to pay attention to differential diagnosis and comorbidities. Clinical psychiatrists have had favorable results in treating children and adolescents with carefully selected and monitored pharmacotherapy.

The studies mentioned by Windaus do not provide more than level of evidence III for psychodynamic psychotherapy for depressive disorders in children and adolescents. One criticism of the quality of these studies is that they include a wide range of very different diagnoses, which are often only partially depression, are often "only" dysthymia, and which include many comorbid disorders. Moreover, the "primary outcome" is not adequately defined and depression-specific scales are hardly used. Thus the conclusions about disorderspecific efficacy are restricted.

It must also be remembered that the high rates of spontaneous remission, the effect of non-specific advice on depression and the placebo response rates from 30 to $60 \%$ can confound results with all forms of treatment (see (1) and (2)). This makes it evident how difficult it is to evaluate the mono-causal efficacy of individual therapeutic strategies. In any case, the level of evidence does not allow the conclusion that specific forms of therapy will or will not work for individual patients. In this context, Windaus's letter may at least be seen as a call for more research in this area.

DOl: 10.3238/arztebl.2008.0364

\section{REFERENCES}

1. Goodyer et al.: Selective serotonin reuptake inhibitors (SSRIs) and routine specialist care with and without cognitive behaviour therapy in adolescents with major depression: randomised controlled trial. BMJ 2007; 21; 335: 142

2. Wilkinson und Goodyer: The effects of cognitive-behavioural therapy on mood-related ruminative response style in depressed adolescents. Child Adolesc Psychiatr Mental Health 2008; 2: 3.

\section{Prof. Dr. med. Claudia Mehler-Wex}

Dr. med. Michael Kölch

Klinik für Kinder- und Jugendpsychiatrie/Psychotherapie

Steinhövelstr. 5

89075 Ulm

Germany

\section{Conflict of interest statement}

The authors declare that no conflict of interest exists according to the guidelines

of the International Committee of Medical Journal Editors. 